\title{
Characterization of Klebsiella isolates obtained from clinical mastitis cases in dairy cattle
}

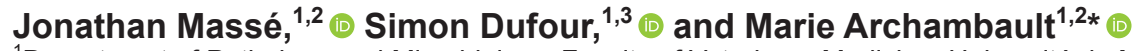 \\ ${ }^{1}$ Department of Pathology and Microbiology, Faculty of Veterinary Medicine, Université de Montréal, \\ Regroupement de Recherche pour un Lait de Qualité Optimale (Op+Lait), Saint-Hyacinthe, Québec, J2S 2M2, Canada \\ ${ }^{2}$ Groupe de Recherche sur les Maladies Infectieuses en Productions Animales (GREMIP), Saint-Hyacinthe, Québec, J2S 2M2, Canada \\ ${ }^{3}$ Mastitis Network, Saint-Hyacinthe, Québec, J2S 2M2, Canada
}

\begin{abstract}
Klebsiella spp. are important opportunistic pathogens commonly defined as environmental clinical mastitis agents. Despite Klebsiella mastitis being clinically impairing in cows and costly to the industry, only a few studies describe Klebsiella isolated from mastitis cases. The aim of this work was to characterize species of Klebsiella involved in clinical mastitis cases in Canada. Klebsiella isolated from clinical mastitis cases $(\mathrm{n}=53)$ were identified to the species level using a biochemical test panel and matrix-assisted laser desorption/ionization time-of-flight mass spectrometry. The rpo $B$ gene sequence was used as the gold standard method and identified Klebsiella pneumoniae $(\mathrm{n}=40)$, Klebsiella oxytoca $(\mathrm{n}=9)$, Raoultella ornithinolytica $(\mathrm{n}=2)$, and Raoultella planticola $(\mathrm{n}=2)$. Raoultella, a genus closely related to Klebsiella, was also accurately identified using mass spectrometry but not via biochemical testing. Using the disc diffusion technique, 31 (58\%) isolates were found to be susceptible to all antimicrobials tested $(\mathrm{n}=18)$. The remaining $22(42 \%)$ isolates were resistant to 1 or more of the following antimicrobials: kanamycin (2\%), streptomycin (38\%), spectinomycin $(13 \%)$, sulfisoxazole $(13 \%)$, and tetracycline (19\%). The following antimicrobial resistance genes were identified: tet $A$, tetB, sul1, strA/strB, and aadA. Random amplified polymorphic DNA revealed the majority of our isolates as unrelated and having different patterns, indicating environmental contamination as the primary source of infection. All isolates were shown to be biofilm producers. In conclusion, although antimicrobial resistance was low for both Klebsiella and Raoultella species, genetically related Klebsiella spp. isolates appeared to be more resistant.
\end{abstract}

Received August 2, 2019.

Accepted December 17, 2019.

*Corresponding author: marie.archambault@umontreal.ca
Key words: cattle, clinical mastitis, Klebsiella, Raoultella

\section{INTRODUCTION}

Klebsiella and Raoultella belong to the Enterobacteriaceae family. They are gram-negative bacteria found in the rumen, in bovine fecal material, and in the dairy environment (Munoz et al., 2007; Zadoks et al., 2011a). Klebsiella is an opportunistic pathogen causing environmental clinical mastitis (Schukken et al., 2012). It is isolated in 2 to $9 \%$ of milk samples from clinical mastitis cases (Olde Riekerink et al., 2008; Oliveira et al., 2013; Levison et al., 2016). Infections of the mammary gland by Klebsiella spp. are characterized by severe clinical signs and poor bacteriological cure rates following administration of antimicrobials (Schukken et al., 2012; Oliveira et al., 2013; Fuenzalida and Ruegg, 2019). Klebsiella infection is also associated with a major decrease in milk production (Gröhn et al., 2004) and thus leads to important economic losses. Affected animals are frequently removed from the herd (Oliveira et al., 2013). The reported pathogenicity in the udder is not well understood, but some virulence determinants have been shown to play a role: $\mathrm{K} 1, \mathrm{~K} 2$, magA (mucoviscosity-associated gene, specific to K1 capsule serotype), uge (uridine diphosphate galactose 4 epimerase encoding gene, responsible for capsule and smooth lipopolysaccharide synthesis), $k f u$ (iron uptake system gene), and the rmpA gene (regulator of the mucoid phenotype; Osman et al., 2014). Because Raoultella is a new genus that was previously classified as Klebsiella (Drancourt et al., 2001), no data is presently available on this bacterium for mastitis in dairy cattle.

In diagnostic laboratories, biochemical tests are frequently used for identification of Klebsiella, and identification beyond the genus level is not often attempted. Molecular techniques such as rpoB sequencing ( $\beta$ subunit of RNA polymerase; Diancourt et al., 2005) would allow for species identification and are commonly 
used in research (Brisse and Duijkeren, 2005; Munoz et al., 2007; Zadoks et al., 2011a). These techniques, however, are time-consuming, expensive, and difficult to implement in a routine diagnostic laboratory. However, MALDI-TOF mass spectrometry offers rapid, precise, and economical routine identification to the species level and is gaining in popularity in veterinary diagnostic laboratories. Moreover, guidelines for this technique are now available from the Clinical and Laboratory Standards Institute (CLSI, 2017). The most important Klebsiella species isolated from the milk of cows with clinical mastitis is Klebsiella pneumoniae, followed by Klebsiella oxytoca (Munoz et al., 2007; Zadoks et al., 2011a,b). One case of Klebsiella variicola has also been reported (Podder et al., 2014).

Klebsiella pneumoniae can also cause many nosocomial infections in humans. It belongs to a group of bacteria frequently associated with antimicrobial resistance (AMR) known as ESKAPE (Enterococcus faecium, Staphylococcus aureus, K. pneumoniae, Acinetobacter baumannii, Pseudomonas aeruginosa, and Enterobacter spp.; Rice, 2010). One of the proposed mechanisms for the persistence of $K$. pneumoniae in human infections is the formation of biofilms, which consist of bacteria embedded in a self-produced polysaccharide matrix (Chung, 2016). The ability to form biofilms has been correlated with AMR (Vuotto et al., 2014). In a study by Schönborn et al. (2017), $84 \%$ of Klebsiella spp. isolates were shown to produce visible quantities of biofilm in a tube method. To our knowledge, this is the only study describing biofilm formation for this pathogen in isolates recovered from bovine mastitis cases. In Klebsiella isolated from bovine milk, AMR is reported as uncommon (Saini et al., 2012b; de Jong et al., 2018), and, when it was present, the genes responsible for the observed resistances were not described. Molecular analysis, as by random amplified polymorphic DNA (RAPD), can assess relatedness of isolates and thereby identify sources and transmission routes for Klebsiella. This analysis has been used to help distinguish between contagious transmission and opportunistic infection from the environment (Munoz et al., 2007; Paulin-Curlee et al., 2008; Podder et al., 2014). The aim of this study was to characterize Klebsiella in clinical mastitis in Canada in terms of microbiological identification and discrimination, AMR, biofilm production, and genetic diversity.

\section{MATERIALS AND METHODS}

\section{Culture Collection}

Isolates were obtained from the Mastitis Pathogen Culture Collection (MPCC) of the Canadian Bovine
Mastitis and Milk Quality Research Network. This collection was assembled during a 2-year cohort study conducted on 91 Canadian dairies. Herd selection, sampling, and bacterial culturing were previously described by Reyher et al. (2011), and the MPCC itself is described by Dufour et al. (2019). Briefly, during that study quarter-milk sample series were collected from apparently normal milking cows and at diagnosis of clinical mastitis. Routine bacteriological milk culture was performed, and Klebsiella spp. were identified based on the following criteria: gram-negative rods, lactose fermentation on MacConkey agar, negative oxidase testing, non-motility, production of urease, utilization of citrate, and usually indole negativity. All Klebsiella spp. isolates recovered in concentration $>1 \mathrm{cfu} / 0.01 \mathrm{~mL}$ and from a plate that was not considered contaminated (i.e., $\geq 3$ phenotypically different types of colonies on the plate) were sent for conservation in the MPCC to the Faculté de médecine vétérinaire of the Université de Montréal. The MPCC contained 194 presumed Klebsiella spp. isolates identified via traditional biochemical methods, and, of these, 139 had some AMR data (Saini et al., 2012b). We selected isolates retrieved from clinical mastitis cases only, and only 1 isolate was included per quarter for each cow presenting clinical mastitis, yielding a total of 53 presumed Klebsiella spp. Verification in our database revealed that isolates came from 21 farms. Frozen isolates were thawed at room temperature, cultured on Columbia agar with $5 \%$ sheep blood (Oxoid, Nepean, Canada), and incubated overnight at $35^{\circ} \mathrm{C}$. A single colony was subcultured on fresh Columbia agar with $5 \%$ sheep blood and incubated overnight at $35^{\circ} \mathrm{C}$.

\section{Species Identification}

Biochemical identification for each isolate was performed using API-20E test strips (Biomérieux, Marcy L'Etoile, France) according to the manufacturer's recommendations. Isolates were also identified via MALDI-TOF using a Microflex LT instrument (Bruker Daltonics, Bremen, Germany). Each isolate was applied on a polished steel MSP 96 target (Bruker Daltonics), extracted with $1 \mu \mathrm{L}$ of $70 \%$ formic acid, and overlaid with $1 \mu \mathrm{L}$ of HCCA matrix before automatic spectra acquisition was launched, using default settings. The instrument was calibrated with a bacterial test standard, and identification to the species level was deemed valid when a score $\geq 2.0$ was obtained. Spectra analyses were conducted using the manufacturer reference database, containing, at the time, 6,903 different spectra. Sequencing of the rpoB gene $(\beta$-subunit of RNA polymerase B) was also performed for specieslevel identification, using primers VIC2 and VIC3, as 
previously described (Diancourt et al., 2005). Following PCR amplification, products migrated in a $1.5 \%$ agarose gel for $25 \mathrm{~min}$ at $150 \mathrm{~V}$. Gels were stained with bromide ethidium and visualized with UV transillumination. A single band at approximately $1,000 \mathrm{bp}$ was present for each isolate and purified by QIAquick PCR purification kit (Qiagen, Hilden, Germany). Purified DNA products were sequenced via pyrosequencing at the Plateforme d'analyse génomique (Université Laval, Québec, Canada). Sequences were manually proofread using SnapGene viewer software (GSL Biotech, Chicago, IL) and were compare with BLAST public database for species identification. Klebsiella pneumoniae ATCC 13883 was used as a control. When identification could not be obtained with the rpoB sequence, $16 \mathrm{~S}$ sequencing was performed at the Animal Health Laboratory (AHL, University of Guelph, Guelph, Canada).

\section{Antimicrobial Susceptibility Testing}

Antimicrobial susceptibility testing for 18 antimicrobials was performed on all isolates of this study, using the disc diffusion method on Mueller Hinton agar, according to CLSI (2018a). The following commercially available discs (Becton Dickinson, Franklin Lakes, NJ) were tested (disc concentrations, breakpoints for susceptibility): amikacin (30 $\mu \mathrm{g}, \geq 17 \mathrm{~mm})$, amoxicillin/ clavulanic acid $(20 / 10 \mu \mathrm{g}, \geq 18 \mathrm{~mm})$, cefoxitin (30 $\mu \mathrm{g}$, $\geq 18 \mathrm{~mm})$, ceftiofur $(30 \mu \mathrm{g}, \geq 21 \mathrm{~mm})$, ceftriaxone (30 $\mu \mathrm{g}, \geq 23 \mathrm{~mm}$ ), cephalotin $(30 \mu \mathrm{g}, \geq 18 \mathrm{~mm}$ ), chloramphenicol $(30 \mu \mathrm{g}, \geq 18 \mathrm{~mm})$, ciprofloxacin $(5 \mu \mathrm{g}, \geq 21$ $\mathrm{mm})$, florfenicol $(30 \mu \mathrm{g}, \geq 19 \mathrm{~mm})$, gentamicin (10 $\mu \mathrm{g}, \geq 15 \mathrm{~mm})$, kanamycin $(30 \mu \mathrm{g}, \geq 18 \mathrm{~mm})$, nalidixic acid, $(30 \mu \mathrm{g}, \geq 19 \mathrm{~mm})$, neomycin $(30 \mu \mathrm{g}, \geq 17 \mathrm{~mm})$, spectinomycin $(100 \mu \mathrm{g}, \geq 14 \mathrm{~mm})$, streptomycin $(10 \mu \mathrm{g}$, $\geq 15 \mathrm{~mm}$ ), sulfamethoxazole/trimethoprim (23.75/1.25 $\mu \mathrm{g}, \geq 16 \mathrm{~mm})$, sulfisoxazole $(250 \mu \mathrm{g}, \geq 17 \mathrm{~mm})$, and tetracycline $(30 \mu \mathrm{g}, \geq 15 \mathrm{~mm})$. Isolates were defined as susceptible, intermediate, or resistant according to CLSI VET08 (CLSI, 2018a) for ceftiofur (breakpoint of Escherichia coli in mastitis), florfenicol, and spectino- mycin (for both, breakpoints of respiratory pathogens in cattle: Mannheimia haemolytica, Histophilus somni, and Pasteurella multocida). For all other antimicrobials, except neomycin and cephalotin, the interpretation was based on human-derived zone diameters for Enterobacteriaceae from CLSI M100 (CLSI, 2018b). Interpretation for cephalotin came from a previous version of CLSI M100 (CLSI, 2012). No zone diameter is available for neomycin; thus, that of amikacin was used ( $<17 \mathrm{~mm}$ indicates resistance). For the current study, intermediate and resistant isolates were grouped together in a "resistant" category.

\section{Genotyping}

Bacteria from a fresh overnight culture was suspended in $100 \mu \mathrm{L}$ of $10 \%$ Chelex (Bio-Rad, Hercules, CA) and heated at $95^{\circ} \mathrm{C}$ for $20 \mathrm{~min}$. After centrifugation at $13,000 \times g$ for $2 \mathrm{~min}$, the supernatant was used as bacterial DNA. All PCR assays were performed in a total volume of $25 \mu \mathrm{L}$ mixture containing the following reagents: $10 \times$ PCR Buffer $(2.5 \mu \mathrm{L}$; New England Biolabs, Ipswich, MA), dNTP $(0.4 \mathrm{mM})$, bacterial DNA $(2.5 \mu \mathrm{L}), \mathrm{MgCl}_{2}(1 \mathrm{~m} M)$, Taq polymerase (1 U), and the corresponding primers for AMR genes (Table 1). After migration on $1.5 \%$ agarose gel for $25 \mathrm{~min}$ at $150 \mathrm{~V}$ with bromide ethidium, all PCR products were visualized using UV transillumination.

To determine relatedness between isolates, RAPD PCR was conducted, using a method previously described by Munoz et al. (2007) and Vogel et al. (1999), with slight modifications. Briefly, ERIC-2/ERIC-1026 primers were used, and thermal conditions were as follows: 2 cycles $\left(94^{\circ} \mathrm{C}\right.$ for $5 \mathrm{~min}, 35^{\circ} \mathrm{C}$ for $5 \mathrm{~min}$, and $72^{\circ} \mathrm{C}$ for $5 \mathrm{~min}$ ), followed by 31 cycles $\left(94^{\circ} \mathrm{C}\right.$ for $1 \mathrm{~min}, 62^{\circ} \mathrm{C}$ for $1 \mathrm{~min}$, and $72^{\circ} \mathrm{C}$ for $2 \mathrm{~min}$ ) and a final extension at $72^{\circ} \mathrm{C}$ for $8 \mathrm{~min}$ (Vogel et al., 1999). After migration on $1.5 \%$ agarose gel with bromide ethidium for $90 \mathrm{~min}$ at $90 \mathrm{~V}$, products were visualized using UV transillumination. The gels were read visually (2 independent readers) to compare banding patterns for each isolate.

Table 1. PCR conditions, primers, and controls for detection of antimicrobial resistance (AMR) genes

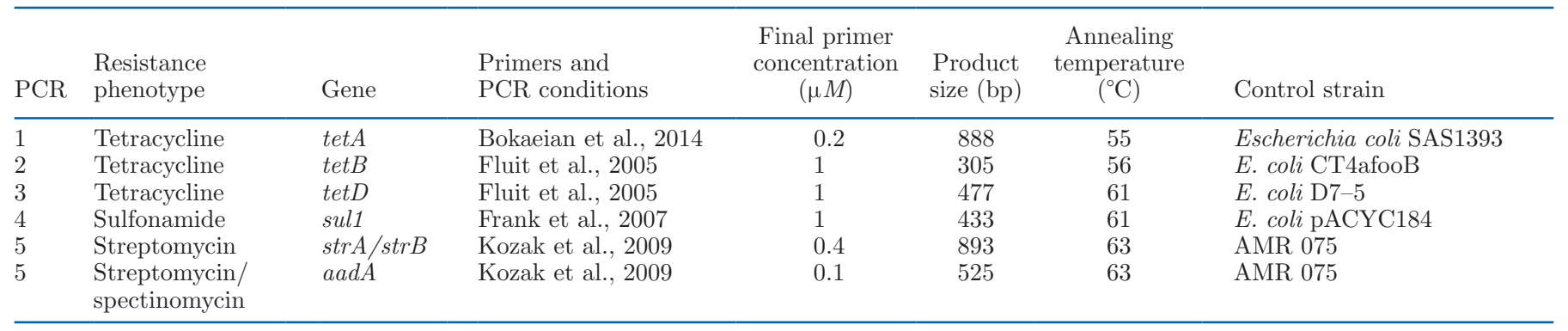


Identical patterns (no band differences) were classified as a single RAPD pattern. Klebsiella pneumoniae ATCC 13883 was used in all reactions as a control.

\section{Biofilm Formation}

Biofilm production and quantification were conducted as described by de Campos et al. (2016), with some modifications. Briefly, 1 colony from an overnight culture was added to $5 \mathrm{~mL}$ of brain heart infusion (BHI) broth and incubated for $24 \mathrm{~h}$ at $35^{\circ} \mathrm{C}$ with rotation at $180 \mathrm{rpm}$. This broth was diluted 1:125 in a fresh $5 \mathrm{~mL}$ of BHI broth, then $200 \mu \mathrm{L}$ was added in triplicate to a 96well flat-bottom polystyrene plate (Costar 3595, Corning Life Sciences, Kennebunk, ME). After static incubation for $24 \mathrm{~h}$ at $35^{\circ} \mathrm{C}$, plates were washed twice with deionized water, and $200 \mu \mathrm{L}$ of crystal violet $0.1 \%$ was added and incubated for $15 \mathrm{~min}$ at room temperature. Plates were washed twice with deionized water and allowed to dry for $30 \mathrm{~min}$ at $35^{\circ} \mathrm{C}$; then $200 \mu \mathrm{L}$ of ethanol $70 \%$ was added for 15 min for elution. Absorbance was read at $570 \mathrm{~nm}$ with a spectrophotometer plate reader. Three independent technical replicates were performed on 3 different days. The negative control was BHI broth without bacteria, and optical density for this control was subtracted to all samples. Two controls (low and high biofilm-forming isolate) were added according to Naparstek et al., (2014). Klebsiella pneumoniae ATCC 13883 and internal control K. pneumoniae 12 were used as controls in each assay. Wells with optical densities greater than 2 times the average of the triplicate were considered contaminated.

\section{Statistical Analysis}

Descriptive statistics and statistical analyses were computed using SPSS Statistics version 25 (IBM Corp.,
Armonk, NY). Comparison of species as functions of different factors (biofilm production, mastitis severity score, DIM, lactation number, and AMR) was performed using the Kruskal-Wallis test for independent samples. Fisher's exact test was used to compare numbers of AMR between 2 groups, according to RAPD type: the first group constituted isolates with similar RAPD patterns (thus, related isolates); the second represented isolates with independent RAPD patterns (thus, the remaining unrelated isolates). An $\alpha$ of 0.05 was considered for inferring statistical significance.

\section{RESULTS}

\section{Bacterial Identification}

Table 2 presents the comparison between biochemical tests, MALDI-TOF, and rpoB sequencing for bacterial identification. The rpoB sequencing could not give an accurate identification for 1 isolate, identified as either K. pneumoniae or K. variicola (506/506 bp for both). Complete 16S RNA sequencing revealed this isolate to be a $K$. pneumoniae $(1,166 / 1,167 \mathrm{bp})$ with a close association to K. variicola (1,164/1,167 bp). Except for this isolate of $K$. pneumoniae mistakenly identified as $K$. variicola by MALDI-TOF, we found no disparities between the MALDI-TOF results and the rpoB sequencing data for Klebsiella and Raoultella spp. On the other hand, biochemical tests could not identify Raoultella planticola and Raoultella ornithinolytica misidentified as $K$. pneumoniae and $K$. oxytoca, respectively.

\section{AMR Phenotypes}

Among the 53 isolates tested, 31 (58\%) were susceptible to all antimicrobials tested. The remaining 22 $(42 \%)$ isolates were resistant to 1 or more of the fol-

Table 2. Comparison between biochemical tests, $r p o B$ sequencing, and MALDI-TOF identification for Klebsiella and Raoultella isolates (n $=$ 53) and their specific characteristics ${ }^{1}$

\begin{tabular}{|c|c|c|c|c|c|c|c|c|}
\hline Species & \multicolumn{3}{|c|}{ Identification technique } & \multicolumn{5}{|c|}{ Average $\pm \mathrm{SD}$} \\
\hline Klebsiella oxytoca & 9 & 10 & 9 & $0.80 \pm 0.85$ & $83 \pm 65$ & $1.8 \pm 0.8$ & $3.0 \pm 1.3$ & $0.7 \pm 1$ \\
\hline Raoultella planticola & 2 & 0 & 2 & $0.68 \pm 0.26$ & $189 \pm 189$ & $1.5 \pm 0.7$ & $2.0 \pm 0.7$ & $1.5 \pm 2.1$ \\
\hline Raoultella ornithinolytica & 2 & 0 & 2 & $0.10 \pm 0.06$ & $149 \pm 49$ & $1.5 \pm 0.7$ & $3.5 \pm 1.4$ & $0.5 \pm 0.7$ \\
\hline
\end{tabular}

${ }^{1} \mathrm{AMR}=$ antimicrobial resistance; OD = optical density.

${ }^{2}$ Mastitis severity scores were attributed by the dairy producer at clinical mastitis diagnosis according to the scale proposed by Sears and McCarthy (2003): 1 = only the milk is abnormal, $2=$ milk and quarter appearance are abnormal, and $3=$ the animal is sick.

${ }^{3}$ Tested for 18 antimicrobials via disc diffusion technique.

${ }^{4}$ RNA 16S identified as K. pneumoniae (1,166/1,167 bp), also closely related to K. variicola $(1,164 / 1,167 \mathrm{bp})$. 
lowing antimicrobials: kanamycin $(2 \%: 1$ K. oxytoca $)$, streptomycin (38\%: $3 \mathrm{~K}$. oxytoca, $16 \mathrm{~K}$. pneumoniae, and 1 R. planticola), spectinomycin (13\%: 1 K. oxytoca, $5 K$. pneumoniae, and $1 R$. planticola), sulfisoxazole (13\%: 1 K. oxytoca, 5 K. pneumoniae, and 1 R. planticola), and tetracycline (19\%: $9 \mathrm{~K}$. pneumoniae, and $1 R$. ornithinolytica; Table 3). Only $1(2 \%) K$. pneumoniae isolate was resistant to 3 antimicrobial classes (aminoglycosides, tetracyclines, and sulfonamides) and thus considered multi-drug resistant (Table 3). Isolates resistant to sulfisoxazole $(\mathrm{n}=7)$ were also resistant to spectinomycin and streptomycin, and vice versa. No resistance to the remaining 13 antimicrobials was observed.

\section{AMR Genotypes}

Table 3 shows the distribution of tested AMR genes tet $A$, tetB, sul1, str $A / \operatorname{str} B$, and aadA found in resistant isolates of Klebsiella and Raoultella. Briefly, all K. pneumoniae and $R$. ornithinolytica that were resistant to tetracycline $(\mathrm{n}=10)$ harbored tet $B$ and tet $A$ genes, respectively. All sulfisoxazole-resistant strains $(\mathrm{n}=7)$ carried the sul1 gene. Of 7 isolates resistant to streptomycin and spectinomycin, 6 harbored the gene aadA. The remaining isolates resistant to streptomycin $(\mathrm{n}=$ 13) harbored the gene $\operatorname{str} A / \operatorname{str} B$. The tetD gene was not present in any of the resistant isolates of Klebsiella or Raoultella.

\section{RAPD Typing}

Overall, 40 RAPD patterns were observed among isolates tested $(\mathrm{n}=53$; Figure 1$)$. From those, 36 unique patterns originated from 20 different farms, and the remaining 4 patterns (A, B, C, and D) contained 8, 3, 2 , and 4 isolates and originated from 2, 2, 1 , and 1 farm or farms, respectively (Table 3 ). Those related isolates showed greater AMR (13 out of 17 were resistant to at least 1 antimicrobial) compared with the 36 unrelated isolates with individual RAPD patterns ( 9 out of 36 were resistant to at least 1 antimicrobial; $P<0.001$ ).

\section{Biofilm Formation}

Klebsiella pneumoniae ATCC 13883 and internal control $K$. pneumoniae 12 were used as relatively low and high biofilm-forming isolates, respectively, with average optical density values of $570 \mathrm{~nm}$ and standard deviations of $0.035 \pm 0.038$ and $1.575 \pm 0.583$, respectively. All Klebsiella and Raoultella in this study were shown to produce biofilms. Figure 2 shows the variable quantities of biofilm observed for each species, and Table 2 presents average biofilm production for each species.

Table 3. Antimicrobial resistance (AMR) phenotypes and genotypes observed in the random amplified polymorphic DNA (RAPD) patterns of this study

\begin{tabular}{|c|c|c|c|c|}
\hline $\begin{array}{l}\text { RAPD patterns } \\
\text { (no. of isolates) }\end{array}$ & $\begin{array}{l}\text { Farms of origin } \\
\text { (no. of isolates) }\end{array}$ & AMR phenotype ${ }^{1}$ & AMR genotype ${ }^{2}$ & Species $^{3}$ \\
\hline \multirow[t]{2}{*}{ A (8) } & Farm $101(5)$ & 5: STR-TET & str $A / \operatorname{str} B-t e t B$ & 5 Klebsiella pneumoniae \\
\hline & Farm 101 (2), farm 103 (1) & 3: None & Not tested & $3 \mathrm{~K}$. pneumoniae \\
\hline B (3) & Farm $103(1)$ & 1: None & Not tested & $1 \mathrm{~K}$. pneumoniae \\
\hline \multirow[t]{2}{*}{$\mathrm{C}(2)$} & Farm 104 (1) & 1: STR-SPE-TET-FIS ${ }^{4}$ & strA/strB-aadA-tetB-sul1 & $1 \mathrm{~K}$. pneumoniae \\
\hline & Farm 104 (1) & 1: STR-TET & str $A / \operatorname{str} B-\operatorname{tet} B$ & $1 \mathrm{~K}$. pneumoniae \\
\hline \multirow{4}{*}{$\begin{array}{l}\text { Other patterns } \\
(36)\end{array}$} & Farm 104 (1), farm 110 (1) & 2: STR-TET & $\operatorname{str} A / \operatorname{str} B-\operatorname{tet} B$ & $2 K$. pneumoniae \\
\hline & Farm $202(1)$ & 1: STR-SPE-FIS & aadA-sul1 & $1 \mathrm{~K}$. oxytoca \\
\hline & Farm 407 (1) & 1: STR-SPE-FIS & Not found-sul1 & 1 R. planticola \\
\hline & Farm 408 (2), farm 310 (1) & 3: STR & $\operatorname{str} A / \operatorname{str} B$ & $\begin{array}{ll}2 & K . \text { oxytoca, } \\
1 & K . \text { pneumoniae }\end{array}$ \\
\hline
\end{tabular}

${ }^{1} \mathrm{STR}=$ streptomycin; TET $=$ tetracycline; FIS = sulfisoxazole; SPE = spectinomycin; KAN = kanamycin.

${ }^{2}$ Antimicrobial resistance genes tested using simplex PCR for $\operatorname{tet} A$, $\operatorname{tet} B$, tet $D$, and $\operatorname{sull}$, and multiplex PCR for $\operatorname{str} A / \operatorname{str} B$ and $a a d A$.

${ }^{3}$ Obtained via rpoB or $16 \mathrm{~S}$ RNA sequencing.

${ }^{4}$ Multidrug resistant patterns. 

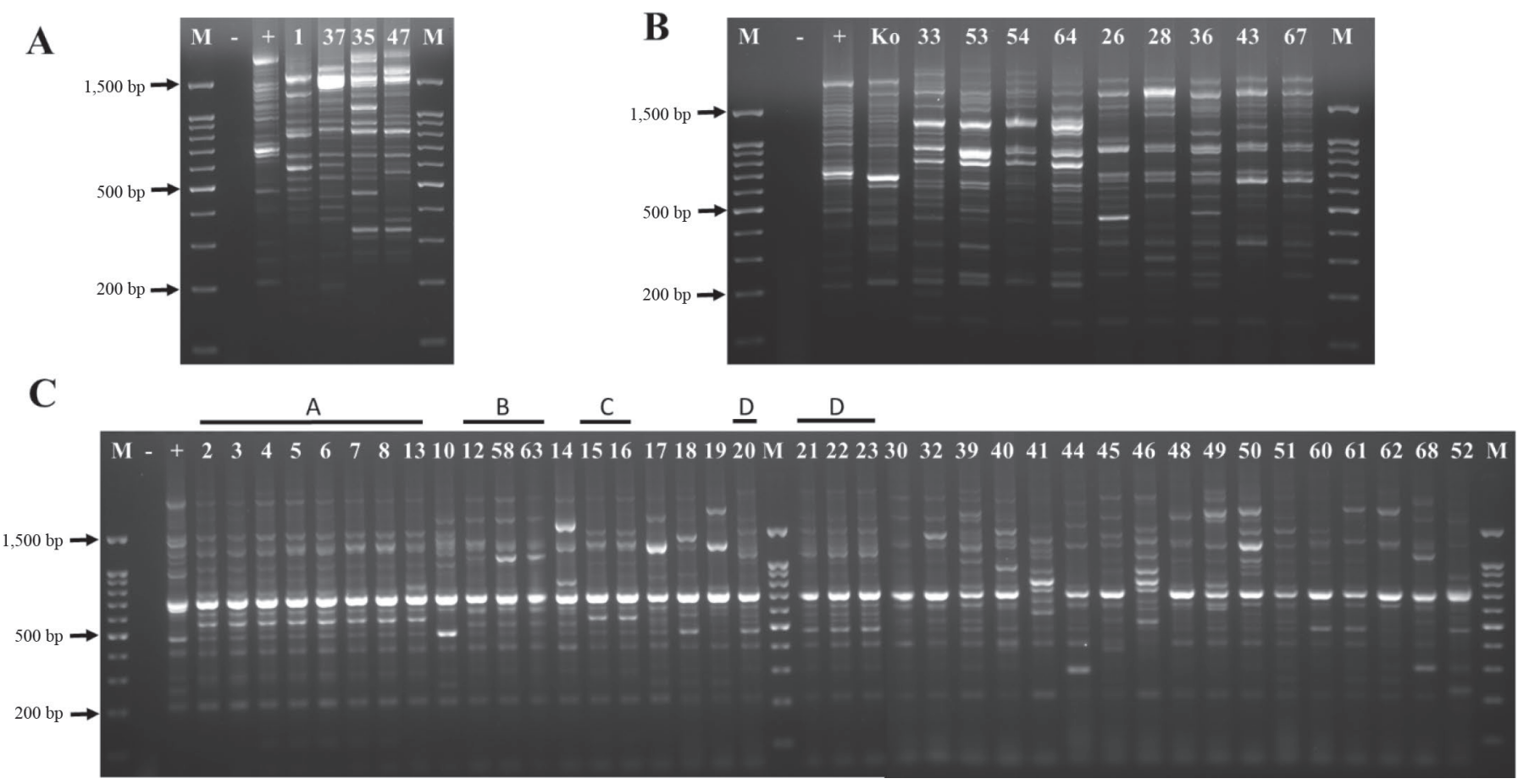

Figure 1. Random amplified polymorphic DNA (RAPD) banding patterns for Klebsiella and Raoultella spp. obtained from dairy cattle clinical mastitis cases. (A) Results for Raoultella ornithinolytica (samples 1 and 37) and Raoultella planticola (samples 35 and 47 ). (B) Results for Klebsiella oxytoca. (C) Results for Klebsiella pneumoniae; letters above the gel represent isolates with the same RAPD banding pattern. One isolate (number 25) is missing due to technical difficulties and is not presented here; however, it was not correlated with any RAPD patterns. $\mathrm{M}=$ molecular weight marker; $-=$ negative control (water); $+=$ positive control (K. pneumoniae ATCC 13883$) ;$ Ko = positive control $(K$. oxytoca ATCC 13182).

Five out of 561 wells were considered contaminated and were excluded from the results.

\section{DISCUSSION}

Mastitis contributes to major economic losses in the dairy industry (Aghamohammadi et al., 2018). The prevalence of mastitis varies between geographical locations due to differences in legislation, veterinary and laboratory services, and management practices (Osman et al., 2014). Among environmental agents causing mastitis, Klebsiella spp. are frequently identified by biochemical tests. As previously reported (Munoz et al., 2007; Zadoks et al., 2011a; Oikonomou et al., 2012), these tests do not yield accurate Klebsiella and Roultella discrimination. As indicated by the name, $R$. ornithinolytica is the only species of the genera Klebsiella or Raoultella positive for ornithine decarboxylase (Drancourt et al., 2001). However, even if the reference strains of $R$. ornithinolytica are positive, most clinical isolates described to date are negative for this test (Walckenaer et al., 2008; Ponce-Alonso et al., 2016), as noted for the $2 R$. ornithinolytica in this study identified via API-20E. The rpoB gene sequencing was described and developed as a valid identification technique for
Klebsiella (Diancourt et al., 2005). It has been used for Klebsiella and Raoultella identification in dairy farms (Munoz et al., 2007; Zadoks et al., 2011a; Podder et al., 2014). In our study, we had only 1 identification

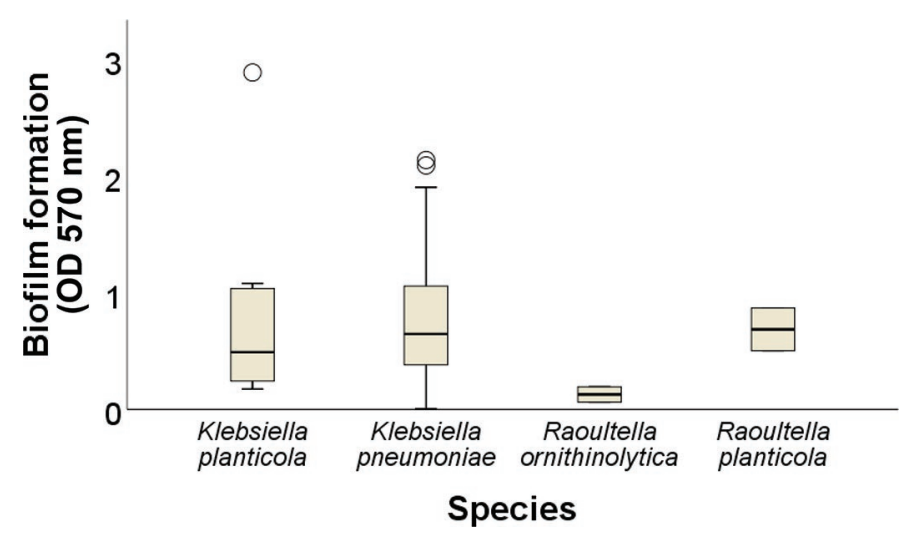

Figure 2. Whisker plot of biofilm formation analyzed by a static technique in 96 wells per plate for Klebsiella and Raoultella spp. obtained from dairy cattle clinical mastitis cases. The midline represents median observation. Lower and upper boxes represent first and third quartile, respectively. Whiskers are minimum and maximum observed values. Empty circles represent outlier observations. OD $570 \mathrm{~nm}=$ optical density at $570 \mathrm{~nm}$. 
problem, regarding an isolate whose $r p o B$ sequence was identical for both $K$. variicola and K. pneumoniae. The final identification had to be confirmed using $16 \mathrm{~S}$ RNA, which was more discriminant for identification of this isolate. In contrast, a past study reported adequate identification for $K$. pneumoniae and $K$. variicola by rроB even if MALDI-TOF could not yield a definitive identification (Munoz et al., 2007). All other identifications in our study were the same between $\operatorname{rpo} B$ and MALDI-TOF, as reported in another study (PonceAlonso et al., 2016), indicating that MALDI-TOF is a suitable alternative to sequencing for identification.

After molecular identification, 1 study reported Raoultella in $4.6 \%$ (11 out of 240) of isolates first identified as Klebsiella (Ponce-Alonso et al., 2016). This concurs with our results of $7.5 \%$ (4/53). The Raoultella genus was created in 2001, after phylogenetic analysis. Before that, it had been classified as Klebsiella (Drancourt et al., 2001). This explains the close relationship between the 2 genera and the difficulty for their accurate differentiation. Raoultella was previously reported on farm environments and in the rumen and manure samples of cows, but not in mastitis cases (Zadoks et al., 2011a; Oikonomou et al., 2012). To our knowledge, this is the first study to publish on Raoultella as a clinical mastitis agent.

In an antimicrobial susceptibility surveillance program conducted in Europe (VetPath; de Jong et al., 2018), low percentages of AMR for Klebsiella spp. isolated from acute mastitis were observed, with the greatest levels of resistance being toward tetracyclines $(19 \%)$. The same tetracycline resistance percentage is reported in this study; however, the most prevalent resistance we observed was toward streptomycin, which was not reported in the European program (de Jong et al., 2018). As previously reported (de Jong et al., 2018), we also did not observe resistance to first-, second-, or third-generation cephalosporins and fluoroquinolones. The most commonly used antimicrobials in 2008 in Canada for clinical mastitis were $\beta$-lactams (Saini et al., 2012a). However, acquired resistance to $\beta$-lactams was not observed in our study. Interestingly, Raoultella was previously described as naturally resistant to ampicillin through a chromosomally encoded class A $\beta$-lactamase (Ponce-Alonso et al., 2016) similar to Klebsiella. In general, the AMR phenotypes observed were well explained by the AMR genes tested, with the exception of 1 isolate that did not carry the aadA gene. The correlation observed between sulfonamide and spectinomycin resistance suggests a common mobile genetic element such as an integron for both sul1 and aadA, as previously reported (Fluit and Schmitz, 2004). Susceptible isolates were not tested for the presence of resistance genes, because they did not express AMR on disc diffusion. In a study by Tyson and colleagues (2015), sensitivity and specificity were higher than $97 \%$ between phenotypes (minimum inhibitory concentration) and genotypes (whole-genome sequencing) in $E$. coli from cattle. The only exception was for streptomycin, for which half of susceptible E. coli carried a resistance gene (Tyson et al., 2015).

Biofilms have been associated with tolerance to antimicrobials (Tremblay et al., 2014). Biofilm production was previously reported for $84 \%$ of Klebsiella spp. isolated from mastitis cases (Schönborn et al., 2017). It is difficult to compare our results with those of Schönborn and colleagues, because the methodologies used in both studies were different. Also, no significant associations were observed between bacterial genus, species, AMR, biofilm production, and cow variable such as mastitis severity score, DIM, and lactation number. In this study, biofilm production has been tested only in isolates from clinical cases and not in isolates from the environment for a comparison.

Interestingly, some isolates with the same RAPD pattern did not have similar AMR genotypes and phenotypes. This suggests that various AMR profiles can be obtained within a unique RAPD pattern, indicating that this technique is not sufficiently discriminant to group DNA fragments associated with AMR. A unique RAPD pattern or closely related RAPD patterns associated with a single farm may indicate contagiousness or a common point-source environmental origin, whereas unrelated patterns are commonly associated with environmental contamination. Previous studies have observed both routes of transmission for Klebsiella on dairy farms (Munoz et al., 2007; Paulin-Curlee et al., 2008; Podder et al., 2014). In our case, the majority of our isolates were unrelated based on RAPD patterns, indicating environmental contamination. Only a small number of isolates showed similar RAPD patterns. Interestingly, isolates with an identical RAPD pattern carried more AMR phenotypes, indicating a possible link between AMR and contagiousness, but this hypothesis warrants further investigation.

\section{CONCLUSIONS}

Characterization of Klebsiella species involved in clinical mastitis cases in Canada revealed that accurate identification was provided by MALDI-TOF. Antimicrobial resistance was generally low, with AMR genes correlating well with AMR phenotypes. All isolates were shown to produce biofilms. This study also determined that environmental contamination was likely the primary source of Klebsiella infection in cows. 


\section{ACKNOWLEDGMENTS}

This work was supported by the Natural Sciences and Engineering Research Council (NSERC) of Canada (M. Archambault, RGPIN-191461; Ottawa, Canada). Jonathan Massé received an undergraduate student research award from NSERC to accomplish this work and a graduate grant from the Regroupement de Recherche Pour un Lait de Qualité Optimale (Op+Lait; Université de Montréal, Saint-Hyacinthe, Canada). We thank Josée Harel (Université de Montréal) and Patrick Boerlin (University of Guelph, Guelph, Canada) for sharing their control strains. We also thank Claudia Duquette, Audrey Charlebois, and Josée Labrie (Université de Montréal) for their technical assistance. The authors have not stated any conflicts of interest.

\section{REFERENCES}

Aghamohammadi, M., D. Haine, D. F. Kelton, H. W. Barkema, H. Hogeveen, G. P. Keefe, and S. Dufour. 2018. Herd-level mastitisassociated costs on Canadian dairy farms. Front. Vet. Sci. 5:100. https://doi.org/10.3389/fvets.2018.00100.

Bokaeian, M., S. Saeidi, Z. Shahi, and V. Kadaei. 2014. tetA and tetB genes in Klebsiella pneumoniae isolated from clinical samples. Gene, Cell and Tissue 1:e18152. https://doi.org/10.17795/ get- 18152 .

Brisse, S., and E. Duijkeren. 2005. Identification and antimicrobial susceptibility of 100 Klebsiella animal clinical isolates. Vet. Microbiol. 105:307-312. https://doi.org/10.1016/j.vetmic.2004.11.010.

Chung, P. Y. 2016. The emerging problems of Klebsiella pneumoniae infections: Carbapenem resistance and biofilm formation. FEMS Microbiol. Lett. 363:fnw219. https://doi.org/10.1093/femsle/ fnw219.

CLSI. 2012. Performance Standards for Antimicrobial Susceptibility Testing. 22nd ed. In CLSI Document M100-22. Clinical and Laboratory Standards Institute, Wayne, PA.

CLSI. 2017. Methods for Identification of Cultured Microorganisms Using Matrix-Assisted Laser Desorption/Ionization Time-of-Flight Mass Spectrometry. 1st ed. In CLSI Guideline M58. Clinical and Laboratory Standards Institute, Wayne, PA.

CLSI. 2018a. Performance Standards for Antimicrobial Disk and Dilution Susceptibility Tests for Bacteria Isolated from Animals. 4th ed. In CLSI supplement VET08. Clinical and Laboratory Standards Institute, Wayne, PA.

CLSI. 2018b. Performance Standards for Antimicrobial Susceptibility Testing. 28th ed. In CLSI Supplement M100. Clinical and Laboratory Standards Institute, Wayne, PA.

de Campos, P. A., S. Royer, D. W. da Fonseca Batistao, B. F. Araujo, L. L. Queiroz, C. S. de Brito, P. P. Gontijo-Filho, and R. M. Ribas. 2016. Multidrug resistance related to biofilm formation in Acinetobacter baumannii and Klebsiella pneumoniae clinical strains from different pulsotypes. Curr. Microbiol. 72:617-627. https://doi.org/ 10.1007/s00284-016-0996-x.

de Jong, A., F. E. Garch, S. Simjee, H. Moyaert, M. Rose, M. Youala, E. Siegwart, and VetPath Study Group. 2018. Monitoring of antimicrobial susceptibility of udder pathogens recovered from cases of clinical mastitis in dairy cows across Europe: VetPath results. Vet. Microbiol. 213:73-81. https://doi.org/10.1016/j.vetmic.2017 .11 .021 .

Diancourt, L., V. Passet, J. Verhoef, P. A. Grimont, and S. Brisse. 2005. Multilocus sequence typing of Klebsiella pneumoniae nosocomial isolates. J. Clin. Microbiol. 43:4178-4182. https://doi.org/10 .1128/JCM.43.8.4178-4182.2005.

Drancourt, M., C. Bollet, A. Carta, and P. Rousselier. 2001. Phylogenetic analyses of Klebsiella species delineate Klebsiella and
Raoultella gen. nov., with description of Raoultella ornithinolytica comb. nov., Raoultella terrigena comb. nov. and Raoultella planticola comb. nov. Int. J. Syst. Evol. Microbiol. 51:925-932. https:// doi.org/10.1099/00207713-51-3-925.

Dufour, S., J. Labrie, and M. Jacques. 2019. The Mastitis Pathogens Culture Collection. Microbiology Resource Announcements 8:e00133-19. https://doi.org/10.1128/MRA.00133-19.

Fluit, A. C., A. Florijn, J. Verhoef, and D. Milatovic. 2005. Presence of tetracycline resistance determinants and susceptibility to tigecycline and minocycline. Antimicrob. Agents Chemother. 49:16361638. https://doi.org/10.1128/AAC.49.4.1636-1638.2005.

Fluit, A. C., and F. J. Schmitz. 2004. Resistance integrons and superintegrons. Clin. Microbiol. Infect. 10:272-288. https://doi.org/10 .1111/j.1198-743X.2004.00858.x.

Frank, T., V. Gautier, A. Talarmin, R. Bercion, and G. Arlet. 2007. Characterization of sulphonamide resistance genes and class 1 integron gene cassettes in Enterobacteriaceae, Central African Republic (CAR). J. Antimicrob. Chemother. 59:742-745. https://doi .org $/ 10.1093 / \mathrm{jac} / \mathrm{dkl} 538$.

Fuenzalida, M. J., and P. L. Ruegg. 2019. Negatively controlled, randomized clinical trial to evaluate intramammary treatment of nonsevere, gram-negative clinical mastitis. J. Dairy Sci. 102:54385457. https://doi.org/10.3168/jds.2018-16156.

Gröhn, Y. T., D. J. Wilson, R. N. Gonzalez, J. A. Hertl, H. Schulte, G. Bennett, and Y. H. Schukken. 2004. Effect of pathogen-specific clinical mastitis on milk yield in dairy cows. J. Dairy Sci. 87:3358 3374. https://doi.org/10.3168/jds.S0022-0302(04)73472-4.

Kozak, G. K., P. Boerlin, N. Janecko, R. J. Reid-Smith, and C. Jardine. 2009. Antimicrobial resistance in Escherichia coli isolates from swine and wild small mammals in the proximity of swine farms and in natural environments in Ontario, Canada. Appl. Environ. Microbiol. 75:559-566. https://doi.org/10.1128/AEM.01821 -08 .

Levison, L. J., E. K. Miller-Cushon, A. L. Tucker, R. Bergeron, K. E. Leslie, H. W. Barkema, and T. J. DeVries. 2016. Incidence rate of pathogen-specific clinical mastitis on conventional and organic Canadian dairy farms. J. Dairy Sci. 99:1341-1350. https://doi.org/10 $.3168 /$ jds.2015-9809.

Munoz, M. A., F. L. Welcome, Y. H. Schukken, and R. N. Zadoks. 2007. Molecular epidemiology of two Klebsiella pneumoniae mastitis outbreaks on a dairy farm in New York State. J. Clin. Microbiol. 45:3964-3971. https://doi.org/10.1128/JCM.00795-07.

Naparstek, L., Y. Carmeli, S. Navon-Venezia, and E. Banin. 2014. Biofilm formation and susceptibility to gentamicin and colistin of extremely drug-resistant KPC-producing Klebsiella pneumoniae. J. Antimicrob. Chemother. 69:1027-1034. https://doi.org/10.1093/ $\mathrm{jac} / \mathrm{dkt} 487$.

Oikonomou, G., V. S. Machado, C. Santisteban, Y. H. Schukken, and R. C. Bicalho. 2012. Microbial diversity of bovine mastitic milk as described by pyrosequencing of metagenomic 16s rDNA. PLoS One 7:e47671. https://doi.org/10.1371/journal.pone.0047671.

Olde Riekerink, R. G., H. W. Barkema, D. F. Kelton, and D. T. Scholl. 2008. Incidence rate of clinical mastitis on Canadian dairy farms. J. Dairy Sci. 91:1366-1377. https://doi.org/10.3168/jds.2007-0757.

Oliveira, L., C. Hulland, and P. L. Ruegg. 2013. Characterization of clinical mastitis occurring in cows on 50 large dairy herds in Wisconsin. J. Dairy Sci. 96:7538-7549. https://doi.org/10.3168/jds $.2012-6078$.

Osman, K. M., H. M. Hassan, A. Orabi, and A. S. Abdelhafez. 2014. Phenotypic, antimicrobial susceptibility profile and virulence factors of Klebsiella pneumoniae isolated from buffalo and cow mastitic milk. Pathog. Glob. Health 108:191-199. https://doi.org/10 $.1179 / 2047773214$ Y.0000000141.

Paulin-Curlee, G. G., S. Sreevatsan, R. S. Singer, R. Isaacson, J. Reneau, R. Bey, and D. Foster. 2008. Molecular subtyping of mastitis-associated Klebsiella pneumoniae isolates shows high levels of diversity within and between dairy herds. J. Dairy Sci. 91:554-563. https://doi.org/10.3168/jds.2007-0479.

Podder, M. P., L. Rogers, P. K. Daley, G. P. Keefe, H. G. Whitney, and K. Tahlan. 2014. Klebsiella species associated with bovine 
mastitis in Newfoundland. PLoS One 9:e106518. https://doi.org/ 10.1371/journal.pone.0106518.

Ponce-Alonso, M., L. Rodriguez-Rojas, R. Del Campo, R. Canton, and M. I. Morosini. 2016. Comparison of different methods for identification of species of the genus Raoultella: Report of 11 cases of Raoultella causing bacteraemia and literature review. Clin. Microbiol. Infect. 22:252-257. https://doi.org/10.1016/j.cmi.2015.10 .035 .

Reyher, K. K., S. Dufour, H. W. Barkema, L. Des Coteaux, T. J. Devries, I. R. Dohoo, G. P. Keefe, J. P. Roy, and D. T. Scholl. 2011. The National Cohort of Dairy Farms - A data collection platform for mastitis research in Canada. J. Dairy Sci. 94:16161626. https://doi.org/10.3168/jds.2010-3180.

Rice, L. B. 2010. Progress and challenges in implementing the research on ESKAPE pathogens. Infect. Control Hosp. Epidemiol. 31(Suppl. 1):S7-S10. https://doi.org/10.1086/655995.

Saini, V., J. T. McClure, D. Leger, S. Dufour, A. G. Sheldon, D. T. Scholl, and H. W. Barkema. 2012a. Antimicrobial use on Canadian dairy farms. J. Dairy Sci. 95:1209-1221. https://doi.org/10.3168/ jds.2011-4527.

Saini, V., J. T. McClure, D. Leger, G. P. Keefe, D. T. Scholl, D. W. Morck, and H. W. Barkema. 2012b. Antimicrobial resistance profiles of common mastitis pathogens on Canadian dairy farms. J. Dairy Sci. 95:4319-4332. https://doi.org/10.3168/jds.2012-5373.

Schönborn, S., N. Wente, J. H. Paduch, and V. Kromker. 2017. In vitro ability of mastitis causing pathogens to form biofilms. J. Dairy Res. 84:198-201. https://doi.org/10.1017/S0022029917000218.

Schukken, Y., M. Chuff, P. Moroni, A. Gurjar, C. Santisteban, F. Welcome, and R. Zadoks. 2012. The "other" gram-negative bacteria in mastitis: Klebsiella, Serratia, and more. Vet. Clin. North Am. Food Anim. Pract. 28:239-256. https://doi.org/10.1016/j .cvfa.2012.04.001.

Sears, P. M., and K. K. McCarthy. 2003. Diagnosis of mastitis for therapy decisions. Vet. Clin. North Am. Food Anim. Pract. 19:93-108. https://doi.org/10.1016/S0749-0720(02)00074-9.

Tremblay, Y. D., V. Caron, A. Blondeau, S. Messier, and M. Jacques. 2014. Biofilm formation by coagulase-negative staphylococci: Impact on the efficacy of antimicrobials and disinfectants commonly used on dairy farms. Vet. Microbiol. 172:511-518. https://doi.org/ 10.1016/j.vetmic.2014.06.007.
Tyson, G. H., P. F. McDermott, C. Li, Y. Chen, D. A. Tadesse, S. Mukherjee, S. Bodeis-Jones, C. Kabera, S. A. Gaines, G. H. Loneragan, T. S. Edrington, M. Torrence, D. M. Harhay, and S. Zhao. 2015. WGS accurately predicts antimicrobial resistance in Escherichia coli. J. Antimicrob. Chemother. 70:2763-2769. https://doi .org/10.1093/jac/dkv186.

Vogel, L., G. Jones, S. Triep, A. Koek, and L. Dijkshoorn. 1999. RAPD typing of Klebsiella pneumoniae, Klebsiella oxytoca, Serratia marcescens and Pseudomonas aeruginosa isolates using standardized reagents. Clin. Microbiol. Infect. 5:270-276. https://doi .org/10.1111/j.1469-0691.1999.tb00140.x.

Vuotto, C., F. Longo, M. P. Balice, G. Donelli, and P. E. Varaldo. 2014. Antibiotic resistance related to biofilm formation in Klebsiella pneumoniae. Pathogens 3:743-758. https://doi.org/10.3390/ pathogens3030743.

Walckenaer, E., V. Leflon-Guibout, and M. H. Nicolas-Chanoine. 2008. How to identify Raoultella spp. including R. ornithinolytica isolates negative for ornithine decarboxylase? The reliability of the chromosomal bla gene. J. Microbiol. Methods 75:405-410. https:// doi.org/10.1016/j.mimet.2008.07.011.

Zadoks, R. N., H. M. Griffiths, M. A. Munoz, C. Ahlstrom, G. J. Bennett, E. Thomas, and Y. H. Schukken. 2011a. Sources of Klebsiella and Raoultella species on dairy farms: Be careful where you walk. J. Dairy Sci. 94:1045-1051. https://doi.org/10.3168/jds.2010-3603.

Zadoks, R. N., J. R. Middleton, S. McDougall, J. Katholm, and Y. H. Schukken. 2011b. Molecular epidemiology of mastitis pathogens of dairy cattle and comparative relevance to humans. J. Mammary Gland Biol. Neoplasia 16:357-372. https://doi.org/10.1007/s10911 $-011-9236-y$.

\section{ORCIDS}

Jonathan Massé @il https://orcid.org/0000-0002-4583-8515

Simon Dufour @ ittps://orcid.org/0000-0001-6418-0424

Marie Archambault @ https://orcid.org/0000-0002-5206-9531 